\title{
Orientações e propostas avaliativas para a escrita alfabética no Programa Nacional do Livro Didático de 2007 a 2016: o que sugerem as coleções de alfabetização?
}

\author{
Magna do Carmo Silva
}

\section{Resumo}

Com o objetivo de verificar se as alterações no tempo de alfabetização implicaram mudanças nas propostas de avaliação para a escrita alfabética, foram analisados o Manual do Professor e o Livro do Aluno de duas coleções de alfabetização aprovadas no Programa Nacional do Livro Didático (PNLD) de 2007 a 2016. A metodologia foi a análise temática de conteúdo. Os resultados indicaram que as coleções apresentam poucas contribuições ao professor quanto à avaliação da escrita alfabética, apesar de considerarem a avaliação como um processo de regulação da prática pedagógica. A conclusão indica que as poucas orientações sobre a forma de registro do processo avaliativo podem fomentar ações docentes que articulem ensino, aprendizagem e avaliação na perspectiva formativa e reguladora da avaliação, considerando os seguintes aspectos: elaboração de critérios avaliativos; utilização de instrumentos adequados; consideração dos erros e dos diversos conhecimentos apresentados pelos alunos; e intervenção junto aos alunos durante e após o processo de ensino.

Palavras-chave: alfabetização; escrita; manual do aluno; manual do professor; Programa Nacional do Livro Didático. 


\section{Abstract \\ Guidelines and evaluative proposals for alphabetical writing in the Programa Nacional do Livro Didático from 2007 to 2016: What do literacy collections propose?}

Aiming to verify whether changes in the time spent on literacy teaching have led to changes on the evaluative proposals for alphabetical writing, the teacher's guide and workbook of two literacy collections approved in the Programa Nacional do Livro Didático (2007 to 2016) have been investigated. The methodology was the thematic content analysis and results indicate that the collections seldom aided the teacher in the evaluation of alphabetical writing, despite considering the evaluation as a process of regulation of pedagogical practice. The conclusion indicates that few guidelines on how to register the evaluation process may propel teaching actions that articulate teaching, learning, and evaluation within a formative and regulative perspective of evaluation, considering the following: elaboration of evaluation criteria; use of appropriate instruments; observation of students' mistakes and other knowledge; and interference with students within the teaching process.

Keywords: literacy; Programa Nacional do Livro Didático; teacher's guide; teaching; textbook; writing.

\section{Resumen \\ Orientaciones y propuestas evaluativas para la escritura alfabética en el Programa Nacional del Libro Didáctico de 2007 a 2016: ¿qué sugieren las colecciones de alfabetización?}

Con el fin de verificar si las alteraciones en el tiempo de alfabetización implicaron cambios en las propuestas de evaluación para la escritura alfabética, se analizaron el Manual del Profesor y el Libro del Estudiante de dos colecciones de alfabetización aprobadas en el Programa Nacional del Libro Didáctico (Programa Nacional do Livro Didático - PNLD) de 2007 a 2016. La metodología fue el análisis temático de contenido. Los resultados indicaron que las colecciones presentan pocas aportaciones al docente en cuanto a la evaluación de la escritura alfabética, a pesar de considerar la evaluación como un proceso de regulación de la práctica pedagógica. La conclusión indica que las pocas orientaciones sobre cómo registrar el proceso de evaluación pueden impulsar acciones docentes que articulen la enseñanza, el aprendizaje y la evaluación en la perspectiva formativa y normativa de la evaluación, considerando los siguientes aspectos: elaboración de criterios de evaluación; uso de instrumentos apropiados; consideración de los errores y de los diversos conocimientos presentados por los estudiantes; e intervención junto a los estudiantes durante el proceso de enseñanza.

Palabras clave: alfabetización; escritura; manual del alumno; manual del profesor; Programa Nacional del Libro didáctico. 


\section{Introdução}

Diferentes programas do Ministério da Educação (MEC) destacam a importância da avaliação da alfabetização como processo contínuo e formativo, a exemplo do Programa Nacional do Livro Didático (PNLD). Este artigo tem, portanto, como objetivo apresentar as orientações e propostas avaliativas para a escrita alfabética presentes em duas coleções de alfabetização aprovadas no Programa (2007 a 2016).

A importância do estudo está no fato de pesquisadores (Albuquerque; Morais, 2011) apontarem que, a partir de 2007, as coleções de alfabetização avançaram em relação a seu ensino na perspectiva do alfabetizar "letrando". Assim, por concebermos que não podemos dissociar os processos de ensino e aprendizagem do processo de avaliação, perguntamos se esse avanço teria ocorrido em relação à proposta de avaliação da escrita alfabética presente nos livros didáticos aprovados. De forma mais específica, temos interesse em aprofundar investigações sobre: o que propõem as orientações do Manual do Professor (MP) sobre a avaliação da escrita alfabética? Como se caracterizam as propostas avaliativas relacionadas à apropriação da escrita alfabética no Livro do Aluno (LA)?

Destacamos a importância do livro didático e sua possível contribuição para a organização da prática avaliativa na alfabetização por meio de orientações sobre instrumentos, critérios, procedimentos de monitoramento das aprendizagens, formas de registro, entre outros elementos que integram o processo avaliativo. Isso se deve, principalmente, ao fato de ele ser distribuído a todas as escolas e turmas de alfabetização, podendo se tornar um elemento importante no processo de orientação das práticas docentes.

\section{Relações entre os processos de ensino, de aprendizagem e de avaliação na alfabetização}

Coll, Marchesi e Palacios (2004) destacam que existem, no mínimo, duas grandes "culturas de avaliação" fortemente arraigadas nos professores de todos os níveis. Uma delas é pautada na separação entre os processos de ensino, aprendizagem e avaliação, e a outra concebe que esses processos se articulam e se complementam. Em relação à primeira cultura, os autores destacam que há ênfase nos êxitos das aprendizagens dos alunos por considerar o processo de aprendizagem em uma perspectiva quantitativa e cumulativa. Nela, a aprendizagem é resultado do reforço sistemático e hierárquico do ensino e do controle das respostas a serem dadas, cabendo à avaliação medir as respostas em relação aos objetivos propostos.

Ainda segundo Coll, Marchesi e Palacios (2004, p. 376), na outra cultura de avaliação, a ênfase é na "aprendizagem como processo que implica mudanças qualitativas na natureza e na organização dos conhecimentos e das capacidades dos alunos". O ensino e a avaliação teriam o papel de conduzir esse processo, por meio de atividades de monitoramento, planejamento, orientação e intervenção. 
Portanto, há uma dicotomia entre as concepções sobre as formas de aprendizagens, sobre as formas de ensino e, consequentemente, sobre as formas de avaliar. De acordo com Depresbiteris e Tavares (2009, p. 41), a avaliação é "parte integrante do ensino e aprendizagem", porém seus fins estão estritamente ligados à concepção do que significa aprender.

Para Zabala (1998), o processo avaliativo tem como foco a aprendizagem da criança, partindo dos critérios avaliativos definidos, e perpassa um planejamento flexível, capaz de se adequar à singularidade dela, a fim de chegar a um resultado que compreenda, valorize e estabeleça novas propostas de intervenção. Por conseguinte, o ato de avaliar, no sentido de promover a criança, é a grande responsabilidade do professor (Hoffmann, 2011). Nessa perspectiva, o erro passa a ser visto como espaço de construção do conhecimento no qual as atividades propostas pelo professor podem servir como subsídios essenciais para a observação das "hipóteses construídas pelo aluno" (Hoffman, 2008, p. 59). Logo, o registro do processo avaliativo é imprescindível para que o professor planeje intervenções e novas formas de acompanhar a aprendizagem da criança, possibilitando-lhe a construção de novos saberes. O ensino e a avaliação cumprem o papel de orientar, intervir, conhecer e ajustar, para que as crianças possam reelaborar essas representações e significados e, consequentemente, construir o conhecimento.

\section{O PNLD e a perspectiva formativa de avaliação}

Historicamente, no Brasil, a alfabetização era realizada por meio do trabalho com um manual didático específico: a cartilha de alfabetização. Segundo Mortatti (2000), obras desse tipo podem ser consideradas como os primeiros livros didáticos, estando vinculadas aos "tradicionais" métodos de alfabetização de base analítica ou sintética. Tais métodos, apesar de diferentes, fundamentavam-se na ideia de língua como código a ser transmitido e memorizado. No referido manual, as atividades propostas traziam implícita a concepção de avaliação como "medida de resultados", visto que as crianças eram treinadas para repetir o que foi memorizado e não havia a proposição de atividades diferenciadas a serem desenvolvidas com elas, considerando a heterogeneidade de conhecimentos da turma.

A partir da década de 1980, por influência dos estudos sobre a psicogênese da língua escrita, as cartilhas passam a ser questionadas e discute-se a possibilidade de os docentes criarem um ambiente alfabetizador que propicie a compreensão da escrita alfabética pelas crianças mediante a interação com diferentes textos escritos em atividades significativas de leitura e produção. Surge, portanto, a necessidade de avaliar a qualidade dos livros destinados ao ensino das crianças nessa etapa escolar.

Diante da importância do livro didático para o professor e das ressignificações das propostas curriculares, o Ministério da Educação e Cultura (MEC) passou a desenvolver, em 1995, o PNLD. A partir desse ano, os livros inscritos no programa passaram a ser submetidos a um trabalho de análise e avaliação pedagógica realizado 
por um grupo de pesquisadores e professores de instituições universitárias, aos quais cabe a tarefa de estabelecer critérios, julgar a qualidade e recomendar/excluir os manuais didáticos (Silva, 2005). No que se refere à alfabetização, desde a implantação do PNLD, já ocorreram dez edições. Os livros inscritos no Programa são avaliados e selecionados de acordo com critérios de natureza conceitual, política e teórico-metodológica. Em todas as edições, os MPs, que acompanham os livros didáticos, também são analisados.

Até o PNLD 2007 (Brasil. FNDE, 2004), os livros de alfabetização eram destinados apenas aos alunos do $1^{\circ}$ ano do ensino fundamental (EF) de oito anos, que recebiam dois livros por ano (o de alfabetização e o primeiro volume da coleção de Língua Portuguesa). Em 2010, o PNLD foi modificado para atender à obrigatoriedade da ampliação do EF para nove anos e a inclusão da criança de 6 anos de idade nessa etapa da escolaridade, prevista na Lei $\mathrm{n}^{\circ} 11.274$, de 6 de fevereiro de 2006, passando a contemplar duas coleções: uma coleção de alfabetização (destinada ao $1^{\circ}$ e $2^{\circ}$ anos do EF) e uma coleção de Língua Portuguesa, destinada ao $3^{\circ}, 4^{\circ}$ e $5^{\circ}$ anos do EF (Brasil. FNDE, 2007). Seguindo o fluxo das mudanças na organização da alfabetização no País com a Portaria no 867, de 4 de julho de 2012, que instituiu o Pacto Nacional pela Alfabetização na Idade Certa (Pnaic), o edital do PNLD 2013 (Brasil. FNDE, 2010) apresenta mudanças na organização da coleção de alfabetização, que passa a envolver três volumes, destinados aos alunos dos três primeiros anos do EF (ciclo de alfabetização). O edital do PNLD 2016 (Brasil. FNDE, 2014) segue o rumo das mudanças propostas pelo PNLD 2013.

Destacamos que, em todos os editais, há a indicação de que o MP deve conter propostas de avaliação e "outras atividades e experimentos, além dos indicados no livro" (Brasil. FNDE, 2004, p. 40), assim como "propostas de atividades individuais e em grupo e sugestões de diferentes formas de avaliação" (Brasil. FNDE, 2004, p. 43). Em relação às atividades do LA, há a expectativa de que seja desenvolvida uma avaliação diagnóstica e processual por meio da sequenciação e da progressão das aprendizagens. Os editais do PNLD 2013 e 2016 propõem que as coleções selecionem e articulem os conteúdos de forma a garantir a progressão do ensino e da aprendizagem, bem como a orientar os professores no que diz respeito à identificação e à avaliação dos conhecimentos adquiridos pelo aluno.

\section{Orientações e propostas avaliativas para a escrita alfabética do PNLD de 2007 a 2016: principais achados}

As coleções do período de 2007 a 2016 marcaram a mudança na organização da alfabetização no Brasil. Assim, o recorte de nossa pesquisa foi do PNLD 2007 ao PNLD 2016 por concebermos a possibilidade de possíveis alterações no tempo de alfabetização implicarem mudanças nas propostas de avaliação para a escrita alfabética presentes nas coleções.

Nossa pesquisa analisou duas coleções: Bem Me Quer (BMQ) e Porta Aberta (POA). As coleções escolhidas estavam entre as cinco aprovadas nos PNLDs de 2007 
a 2016. Ao todo foram analisados 18 LAs e 18 MPs, conforme indicamos: no PNLD 2007, o livro de alfabetização de cada coleção (1 ano do EF); no PNLD 2010, dois LAs e MPs em cada coleção ( $1^{\circ}$ e $2^{\circ}$ anos do EF); nos PNLD 2013 e PNLD 2016, três LAs e MPs de cada coleção $\left(1^{\circ}, 2^{\circ}\right.$ e $3^{\circ}$ anos do EF).

Para analisar as coleções de alfabetização do PNLD, adotamos como procedimento metodológico a análise documental (Ludke; André, 1986). O tratamento dos dados obtidos empregou, basicamente, a análise temática de conteúdo (Bardin, 1977), utilizando processos de descrição, inferência e interpretação, que consistem em um recurso técnico de análise de dados obtidos em mensagens escritas ou transcritas. Os procedimentos dessa análise foram desenvolvidos em quatro momentos: pré-análise, exploração do material, tratamento dos resultados obtidos e interpretação.

As categorias elaboradas das análises realizadas no MP foram organizadas em:

1) concepções de avaliação da aprendizagem para o ciclo de alfabetização;

2) diferentes atividades avaliativas e qualidade dessas propostas para o ciclo de alfabetização;

3) tratamento didático dado pelos autores ao erro como processo de aprendizagem no ciclo de alfabetização;

4) orientações quanto ao processo avaliativo para o ciclo de alfabetização;

5) consideração da heterogeneidade de concepções dos aprendizes e avaliação de seus processos no ciclo de alfabetização.

As categorias utilizadas na análise do LA foram:

1) quantitativo de atividades avaliativas;

2) tipos de atividades com foco avaliativo;

3) modo de execução;

4) finalidade;

5) qualidade da orientação presente nas atividades avaliativas.

\section{Orientações sobre a avaliação da escrita alfabética no MP}

Os MPs das coleções de alfabetização dos PNLDs 2007 a 2016 apresentam em seus princípios teóricos uma proposta articulada de alfabetização e letramento. No entanto, encontramos poucas contribuições referentes às concepções e orientações relacionadas à avaliação da escrita alfabética.

Todas as coleções partem da concepção de que a avaliação é um processo coletivo e tem como objetivo regular e adequar a prática pedagógica às necessidades dos alunos de forma contínua, diagnóstica, mediadora, qualitativa, informativa. Contudo, observamos que há um distanciamento entre os pressupostos teóricos no MP e o que é apresentado como proposta efetiva no LA.

As duas coleções enfatizam a perspectiva formativa de avaliação, porém não a materializam, pois trazem orientações superficiais sobre o processo avaliativo da 
escrita, relacionado a o que, como, por que e para que avaliar, bem como sobre as formas de registro. Há ausência de orientações sobre como o professor deve trabalhar a heterogeneidade e o erro do aluno e, também, quanto à progressão do ensino e avaliação do conteúdo ao longo do ano e dos anos.

Destacamos, ainda, que há uma concordância, nas coleções, de que deve haver integração entre ensino, avaliação e aprendizagem, planejamento da avaliação, tratamento do erro, registro do processo e propostas de intervenção adequadas. No entanto, os MPs fazem apenas considerações gerais sobre esse processo avaliativo, não especificando como se operacionalizariam esses elementos em relação à escrita alfabética.

A falta de sistematização das orientações para o processo avaliativo da escrita alfabética nos MPs é preocupante, tendo em vista que os editais do PNLD (principalmente após a edição de 2013) enfatizam a necessidade de as coleções trazerem subsídios aos docentes em relação ao processo avaliativo.

\section{Propostas avaliativas nas coleções de alfabetização}

A análise das coleções de alfabetização revelou a presença de muitas atividades para a apropriação da escrita alfabética nas coleções BMQ e POA em todos os PNLDs. Porém, identificamos que poucas possuíam foco avaliativo (Tabela 1).

Tabela 1 - Quantidade de atividades avaliativas nas coleções

\begin{tabular}{|c|c|c|c|c|c|c|c|c|c|}
\hline \multirow{3}{*}{$\begin{array}{c}\text { Atividades } \\
\text { de escrita } \\
\text { alfabética }\end{array}$} & \multirow{2}{*}{$\begin{array}{c}\text { PNLD } \\
2007 \\
1^{\circ} \text { ano } \\
\end{array}$} & \multicolumn{2}{|c|}{$\begin{array}{c}\text { PNLD } \\
2010 \\
\end{array}$} & \multicolumn{3}{|c|}{$\begin{array}{c}\text { PNLD } \\
2013 \\
\end{array}$} & \multicolumn{3}{|c|}{$\begin{array}{r}\text { PNLD } \\
2016 \\
\end{array}$} \\
\hline & & $1^{\circ}$ ano & $2^{\circ}$ ano & $1^{\circ}$ ano & $2^{\circ}$ ano & $3^{\circ}$ ano & $1^{\circ}$ ano & $2^{\circ}$ ano & $3^{\circ}$ ano \\
\hline & Quant. & Quant. & Quant. & Quant. & Quant. & Quant. & Quant. & Quant. & Quant. \\
\hline \multicolumn{10}{|c|}{ Coleção BMQ } \\
\hline $\begin{array}{l}\text { Foco no } \\
\text { ensino }\end{array}$ & 210 & 180 & 135 & 256 & 236 & 164 & 151 & 148 & 111 \\
\hline $\begin{array}{l}\text { Foco na } \\
\text { avaliação }\end{array}$ & 03 & 03 & 03 & 30 & 13 & 12 & 44 & 31 & 21 \\
\hline \multicolumn{10}{|c|}{ Coleção POA } \\
\hline $\begin{array}{l}\text { Foco no } \\
\text { ensino }\end{array}$ & 305 & 307 & 198 & 342 & 226 & 185 & 192 & 153 & 96 \\
\hline $\begin{array}{l}\text { Foco na } \\
\text { avaliação }\end{array}$ & 61 & 63 & 27 & 78 & 33 & 20 & 75 & 47 & 31 \\
\hline
\end{tabular}

Fonte: Elaboração própria.

Explicitaremos melhor como se configuram essas atividades avaliativas:

a) Tipo de atividade com foco avaliativo

A tabela 2 apresenta, em cada edição do PNLD, o total de atividades que trazem no enunciado do LA um comando relacionado à avaliação e as que trazem orientação no MP sobre o processo avaliativo envolvido na atividade proposta. 
Tabela 2 - Quantidade de atividades com foco avaliativo nas coleções

\begin{tabular}{|c|c|c|c|c|c|c|c|c|c|}
\hline \multirow{3}{*}{ Atividades } & \multirow{2}{*}{\begin{tabular}{|c|} 
PNLD \\
2007 \\
$1^{\circ}$ ano \\
\end{tabular}} & \multicolumn{2}{|c|}{$\begin{array}{c}\text { PNLD } \\
2010 \\
\end{array}$} & \multicolumn{3}{|c|}{$\begin{array}{c}\text { PNLD } \\
2013 \\
\end{array}$} & \multicolumn{3}{|c|}{$\begin{array}{r}\text { PNLD } \\
2016 \\
\end{array}$} \\
\hline & & $1^{\circ}$ ano & $2^{\circ}$ ano & $1^{\circ}$ ano & $2^{\circ}$ ano & $3^{\circ}$ ano & $1^{\circ}$ ano & $2^{\circ}$ ano & $3^{\circ}$ ano \\
\hline & Quant. & Quant. & Quant. & Quant. & Quant. & Quant. & Quant. & Quant. & Quant. \\
\hline \multicolumn{10}{|c|}{ Coleção BMQ } \\
\hline No LA & 03 & 02 & 03 & 16 & 11 & 12 & 23 & 21 & 14 \\
\hline No MP & 0 & 01 & 0 & 14 & 02 & 0 & 19 & 10 & 07 \\
\hline Total & 03 & 03 & 03 & 30 & 13 & 12 & 44 & 31 & 21 \\
\hline \multicolumn{10}{|c|}{ Coleção POA } \\
\hline No LA & 10 & 03 & 0 & 05 & 04 & 14 & 19 & 10 & 03 \\
\hline No MP & 51 & 60 & 27 & 73 & 29 & 06 & 56 & 37 & 28 \\
\hline Total & 61 & 63 & 27 & 78 & 33 & 20 & 75 & 47 & 31 \\
\hline
\end{tabular}

Fonte: Elaboração própria.

Percebemos uma quantidade maior de atividades e orientações avaliativas sobre a escrita alfabética nos PNLDs mais recentes (2013 e 2016), em detrimento do PNLD 2007. Provavelmente, isso se deve à influência do ciclo de alfabetização e a considerações quanto à progressão do ensino, da aprendizagem e da avaliação ao longo dos anos.

No geral, as atividades avaliativas estão caracterizadas conforme a Tabela 3.

Tabela 3 - Tipos de atividades avaliativas presentes nas coleções analisadas

\begin{tabular}{|c|c|c|c|c|c|c|}
\hline \multirow{2}{*}{ Categorias } & \multirow{2}{*}{ Subcategorias } & \multirow{2}{*}{$\begin{array}{l}\text { Modelos de questões encontradas em todas as } \\
\text { coleçóes BMQ e POA - PNLD } 2007 \text { a } 2016\end{array}$} & \multicolumn{3}{|c|}{ Quantidade } & \multirow[b]{2}{*}{ Total } \\
\hline & & & $1^{\circ}$ & $2^{\circ}$ & $3^{\circ}$ & \\
\hline \multirow{12}{*}{$\begin{array}{l}\text { Tipo de } \\
\text { atividade } \\
\text { avaliativa }\end{array}$} & \multirow{7}{*}{$\begin{array}{l}\text { Comando } \\
\text { avaliativo no } \\
\text { enunciado } \\
\text { (LA) }\end{array}$} & $\begin{array}{l}\text { Revisão/correção/reescrita de palavras com foco } \\
\text { na apropriação da escrita alfabética ou } \\
\text { ortográfica. }\end{array}$ & 13 & 0 & 02 & 15 \\
\hline & & $\begin{array}{l}\text { Revisão/correção/reescrita de frases ou palavras } \\
\text { com foco na análise linguística. }\end{array}$ & 4 & 0 & 02 & 06 \\
\hline & & $\begin{array}{l}\text { Avaliação pelo professor do processo de } \\
\text { aprendizagem do aluno. }\end{array}$ & 73 & 44 & 32 & 149 \\
\hline & & $\begin{array}{l}\text { Avaliação pelo aluno do seu processo de } \\
\text { aprendizagem. }\end{array}$ & 16 & 12 & 07 & 35 \\
\hline & & $\begin{array}{l}\text { Identificação pelo aluno de critérios usados } \\
\text { pelos colegas para escrever. }\end{array}$ & 06 & 0 & 0 & 06 \\
\hline & & $\begin{array}{l}\text { Verificação pelo aluno sobre a qualidade das } \\
\text { respostas dadas. }\end{array}$ & 13 & 02 & 0 & 15 \\
\hline & & Descrição pelo aluno de seu processo avaliativo. & 0 & 01 & 01 & 02 \\
\hline & \multirow{5}{*}{$\begin{array}{l}\text { Comando } \\
\text { avaliativo na } \\
\text { orientação } \\
\text { ao professor } \\
\text { (MP) }\end{array}$} & $\begin{array}{l}\text { Auxiliar o aluno na realização da atividade (ora } \\
\text { propondo reflexão, ora apenas determinando o } \\
\text { que fazer). }\end{array}$ & 74 & 27 & 12 & 113 \\
\hline & & $\begin{array}{l}\text { Promover explicitamente a autoavaliação do } \\
\text { aluno. }\end{array}$ & 25 & 04 & 0 & 29 \\
\hline & & $\begin{array}{l}\text { Promover explicitamente a heteroavaliação } \\
\text { entre os alunos. }\end{array}$ & 25 & 03 & 01 & 29 \\
\hline & & $\begin{array}{l}\text { Avaliar o conhecimento do aluno sem indicar } \\
\text { que está realizando esta ação. }\end{array}$ & 98 & 43 & 23 & 164 \\
\hline & & $\begin{array}{l}\text { Avaliar o conhecimento do aluno, com a } \\
\text { justificativa dos alunos sobre as respostas ou } \\
\text { decisões tomadas ao responder. }\end{array}$ & 10 & 05 & 04 & 19 \\
\hline \multicolumn{3}{|c|}{ Total geral das atividades avaliativas por ano } & 357 & 141 & 84 & 582 \\
\hline
\end{tabular}

Fonte: Elaboração própria. 
De forma mais específica, a análise dos resultados mostra que a maioria das atividades (25,6\% nos enunciados e $28,2 \%$ nas orientações ao professor) solicita ao professor que avalie o conhecimento do aluno, sem pressupor algum tipo de interação ou feedback.

Além disso, em relação às atividades avaliativas presentes no enunciado, destacamos que a autoavaliação da escrita pelo aluno teve um percentual de 6\%, entre todas as atividades encontradas, o que indica um índice muito pequeno, tendo em vista que essa é uma habilidade importante no processo avaliativo.

Ainda em relação às atividades presentes no LA, foram encontradas poucas atividades relativas a: revisão/correção/reescrita de palavras com foco na apropriação da escrita alfabética ou ortográfica (2,6\%); revisão/correção/reescrita de frases ou palavras com foco na análise linguística (1\%); identificação de critérios usados pelos colegas para escrever (1\%); verificação sobre a qualidade das respostas dadas $(2,6 \%)$; e descrição pelo aluno de seu processo avaliativo (0,4\%). Apesar dos baixos percentuais, destacamos que a presença desse tipo de atividade demonstra como o processo avaliativo pode ficar mais explícito à criança no LA.

As outras propostas presentes nas orientações ao docente solicitavam que o professor ajudasse o aluno a realizar a atividade (19,5\%), muitas vezes de forma mecânica, ou promovesse a autoavaliação (5\%) e a heteroavaliação (5\%) entre os alunos. Em apenas 3,2\% das situações propostas, foram encontradas atividades nas quais o professor foi instigado a solicitar que os alunos justificassem as respostas.

Uma análise minuciosa das atividades presentes na Tabela 3, considerando as atividades presentes no LA e as orientações ao professor, indica que o modo de execução dessas atividades, na sua maior parte $(73,2 \%)$, é focada na heteroavaliação entre aluno e professor e, nesse caso, caberia ao docente a tarefa de apenas conferir o conhecimento do estudante; por exemplo, situações em que o professor: usa as atividades de escrita de palavras como diagnóstico e registro dos avanços individuais, por meio de exercício de fixação ( $1^{\circ}$ ano, POA); verifica se os alunos escreveram adequadamente e se têm dúvidas quanto à grafia das palavras ( $2^{\circ}$ ano, $\mathrm{BMQ}$ ); é solicitado a percorrer as bancas dos alunos e se certificar se os critérios usados para a leitura de palavras estão adequados ( $3^{\circ}$ ano, BMQ).

Ainda em relação ao modo de execução implícito no total de atividades presentes na Tabela 3 , um menor percentual $(9,3 \%)$ destinou-se às atividades de heteroavaliação entre os alunos. Algumas dessas atividades solicitavam que eles: comparassem a resposta em relação à escrita alfabética, discutindo as diferentes hipóteses ( $1^{\circ}$ ano, $\mathrm{POA}$ ); trabalhassem em duplas para discutir sobre a forma correta de escrever ou de completar as palavras com sílabas ( $1^{\circ}$ ano, BMQ); conversassem com os colegas sobre a realização da atividade e avaliassem o que aprenderam sobre o conteúdo relacionado à formação de palavras com letras móveis ( $2^{\circ}$ ano, BMQ). Atividades desse tipo são importantes por permitirem a verificação de respostas e o levantamento/confronto das hipóteses de escrita entre os alunos.

Por fim, as atividades de autoavaliação (17,5\%), presentes no total de atividades da Tabela 3, tinham como foco pedir ao aluno que: falasse sobre o que aprendeu com a atividade de formação de sílabas ( $1^{\circ}$ ano, POA); justificasse sua 
resposta em relação à escrita de palavras ( $2^{\circ}$ ano, POA); e escrevesse qual procedimento usaria para se certificar que escreveu corretamente as palavras ditadas com dígrafos e sílabas complexas ( $3^{\circ}$ ano, $\mathrm{POA}$ ).

b) Finalidade das atividades avaliativas

A Tabela 4 foi construída com base na análise da finalidade das atividades propostas.

Tabela 4 - Finalidade das atividades com foco avaliativo nas coleções

\begin{tabular}{|c|c|c|c|c|c|c|c|c|c|c|}
\hline \multirow{3}{*}{ Atividades } & \multirow{2}{*}{\begin{tabular}{|c|}
$\begin{array}{c}\text { PNLD } \\
2007\end{array}$ \\
$1^{\circ}$ ano \\
\end{tabular}} & \multicolumn{2}{|c|}{$\begin{array}{l}\text { PNLD } \\
2010\end{array}$} & \multicolumn{3}{|c|}{$\begin{array}{l}\text { PNLD } \\
2013\end{array}$} & \multicolumn{3}{|c|}{$\begin{array}{l}\text { PNLD } \\
2016\end{array}$} & \multirow{3}{*}{$\begin{array}{l}\text { Total por } \\
\text { finalidade }\end{array}$} \\
\hline & & $1^{\circ}$ ano & $2^{\circ}$ ano & $1^{\circ}$ ano & $2^{\circ}$ ano & $3^{\circ}$ ano & $1^{\circ}$ ano & $2^{\circ}$ ano & $3^{\circ}$ ano & \\
\hline & Quant. & Quant. & Quant. & Quant. & Quant. & Quant. & Quant. & Quant. & Quant & \\
\hline \multicolumn{11}{|c|}{ Coleção BMQ } \\
\hline Verificação & 0 & 0 & 0 & 12 & 07 & 10 & 26 & 16 & 09 & 80 \\
\hline $\begin{array}{l}\text { Promover } \\
\text { reflexão }\end{array}$ & 03 & 03 & 03 & 18 & 06 & 02 & 18 & 15 & 12 & 80 \\
\hline $\begin{array}{l}\text { Total } \\
\text { geral }\end{array}$ & 03 & 03 & 03 & 30 & 13 & 12 & 44 & 31 & 21 & 160 \\
\hline \multicolumn{11}{|c|}{ Coleção POA } \\
\hline Verificação & 45 & 34 & 13 & 27 & 18 & 13 & 42 & 30 & 23 & 245 \\
\hline $\begin{array}{l}\text { Promover } \\
\text { reflexão }\end{array}$ & 16 & 29 & 14 & 51 & 15 & 07 & 33 & 17 & 08 & 175 \\
\hline $\begin{array}{l}\text { Total } \\
\text { geral }\end{array}$ & 61 & 63 & 27 & 78 & 33 & 20 & 75 & 47 & 31 & 420 \\
\hline
\end{tabular}

Fonte: Elaboração própria.

Os resultados apontam que a maioria das atividades avaliativas apenas incita o professor a verificar o conhecimento construído e não sugere o confronto de hipóteses entre os pares ou o aprofundamento das discussões por meio de uma reflexão.

Os dados indicam, ainda, que a coleção POA contém maior número de atividades que estimulam a revisão das produções dos alunos, a ampliação dos conhecimentos pelas trocas entre eles e o aprofundamento das questões. Apesar de a coleção BMQ, em relação à coleção POA, possuir um número menor de atividades com a finalidade de promover a reflexão, as atividades encontradas naquela coleção, em todos os PNLDs, contribuem para a efetivação do processo avaliativo da escrita, por parte do professor, ao estimularem que os estudantes reflitam sobre os conhecimentos produzidos.

c) Qualidade da orientação

Em linhas gerais, identificamos um avanço entre os PNLDs nas duas coleções, com um aumento no número de atividades voltadas para a consideração do erro e da heterogeneidade da turma. Contudo, poucas atividades, nas duas coleções, apresentam qualidade quanto à orientação presente no MP, com referência à consideração da diversidade de conhecimento sobre a escrita dos alunos que, porventura, não consigam realizar as atividades propostas. Entre todas as atividades encontradas no MP, apenas 
72 tinham esse tipo de orientação na coleção POA e 21 na BMQ. Da mesma forma, foi encontrado no MP da coleção BMQ um baixo quantitativo de atividades (22) que tratam de orientações sobre o erro do aluno, em relação à coleção POA (147).

Apesar da escassez de orientações qualitativas, em ambas as coleções, encontramos algumas orientações que podem auxiliar o docente: 1) em uma atividade do $2^{\circ}$ ano (BMQ, 2016), cujo foco é a "orientação para aceitar as respostas dos alunos diferentes das propostas no livro didático, desde que coerentes", o MP permite ao professor não só identificar os alunos que apresentem dificuldades sobre o objeto de ensino da escrita, como também o orienta a fazer intervenções adequadas para que os aprendentes as superem, independentemente do ritmo de aprendizagem de cada um; e 2) em uma das atividades analisadas na POA ( $2^{\circ}$ ano, 2016), o MP propõe ao docente que ajude individualmente os alunos na atividade por meio de questõesproblema relacionadas às hipóteses deles ou os oriente como lidar com o próprio erro.

\section{Considerações finais}

Se resgatarmos as questões elencadas no início deste texto, concluiremos que há um caminho a percorrer quanto à operacionalização da avaliação da escrita alfabética no âmbito das coleções de alfabetização aprovadas no PNLD e por nós analisadas. Com base nos resultados da pesquisa realizada, percebemos que as orientações e propostas avaliativas da escrita alfabética se configuram de forma genérica nas coleções de alfabetização sucessivamente aprovadas do PNLD 2007 ao PNLD 2016.

Consideramos, então, os dados produzidos no estudo como indicadores de que tanto o MP como o LA não subsidiam a prática docente de avaliação da escrita alfabética. Isso porque os MPs analisados trazem orientações superficiais relacionadas a o que, como, por que e para que avaliar, bem como às formas de registro desse processo, o que representa uma ausência de proposta específica para o planejamento da avaliação numa perspectiva de progressão, conforme tratam os editais do PNLD.

Além disso, há pouca informação sobre como o professor deve lidar com a heterogeneidade e o erro do aluno no processo de ensino e de aprendizagem dessa escrita, cabendo apenas ao docente avaliar os alunos e propor encaminhamentos para lidar com as diversas formas de compreender e fazer uso dela. Da mesma maneira, o LA enfatiza atividades que buscam apenas verificar se os alunos construíram as informações esperadas (de forma individual e coletiva), sem propor reflexão sobre os processos vivenciados e as diversas possibilidades de respostas.

Apesar de percebermos certa ausência de elementos sistemáticos para a regulação do processo de ensino e de aprendizagem na alfabetização, a pesquisa aponta rumos para novas reflexões. Os tipos de atividades encontradas, os agrupamentos e as finalidades propostas, bem como as orientações incipientes indicam caminhos para que as discussões fomentem ações docentes que articulem ensino, aprendizagem e avaliação na perspectiva formativa e reguladora da avaliação da escrita alfabética nos seguintes aspectos: 
- elaboração de critérios avaliativos;

- utilização de instrumentos avaliativos adequados;

- consideração dos erros e dos diversos conhecimentos apresentados pelos alunos; e

- intervenção junto aos alunos durante e após o processo de ensino.

Dessa forma, este artigo tem a intenção de contribuir para a discussão sobre a necessidade de que os processos avaliativos da aprendizagem da escrita, presentes nos livros didáticos, sejam mais explícitos aos professores e alunos.

\section{Referências bibliográficas}

ALBUQUERQUE, E. B. C.; MORAIS, A. G. Os livros didáticos na alfabetização: mudanças e possibilidades de uso. In: LEAL, T. F.; SILVA, A. (Org.). Recursos didáticos e ensino de Língua Portuguesa: computadores, livros... e muito mais. Belo Horizonte: CRV, 2011. p. 135-156.

BARDIN, L. Análise de conteúdo. Lisboa: Edições 70, 1977.

BRASIL. Lei no 11.274, de 6 de fevereiro de 2006. Altera a redação dos arts. 29, 30, 32 e 87 da Lei n 9.394, de $^{\circ} 0$ de dezembro de 1996, que estabelece as diretrizes e bases da educação nacional, dispondo sobre a duração de 9 (nove) anos para o ensino fundamental, com matrícula obrigatória a partir dos 6 (seis) anos de idade. Diário Oficial da União, Brasília, DF, 7 fev. 2006. Seção 1, p. 3.

BRASIL. Fundo Nacional de Desenvolvimento da Educação (FNDE). Programa Nacional do Livro Didático para o ano de 2007: PNLD/2007: edital de convocação para inscrição no processo de avaliação e seleção de obras didáticas a serem incluídas no guia de livros didáticos de 1ª a 4ª série do PNLD/2007. Brasília, 2004. Disponível em: < https://cchla.ufrn.br/pnld/wp-content/uploads/edital_pnld_20074.pdf>. Acesso em: 5 ago. 2020.

BRASIL. Fundo Nacional de Desenvolvimento da Educação (FNDE). Programa Nacional do Livro Didático: PNLD 2010: edital de convocação para inscrição no processo de avaliação e seleção de obras didáticas para o programa nacional do livro didático: PNLD 2010. Brasília, 2007. Disponível em: <ftp://ftp.fnde.gov.br/ web/livro_didatico/edital_pnld_2010.pdf>. Acesso em: 5 ago. 2020.

BRASIL. Fundo Nacional de Desenvolvimento da Educação (FNDE). Programa Nacional do Livro Didático: PNLD 2013: edital de convocação para o processo de inscrição e avaliação de obras didáticas para o Programa Nacional do Livro Didático: PNLD 2013. Brasília, 2010. Disponível em: <http://www. fnde.gov.br/index.php/centrais-de-conteudos/publicacoes/category/165editais?download=5024:pnld-2013-edital>. Acesso em: 5 ago. 2020.

BRASIL. Fundo Nacional de Desenvolvimento da Educação (FNDE). Edital de convocação 02/2014: edital de convocação para o processo de inscrição e avaliação 
de obras didáticas para o Programa Nacional do Livro Didático: PNLD 2016. Brasília, 2014. Disponível em: < https://www.fnde.gov.br/index.php/centrais-de-conteudos/ publicacoes/category/165-editais?download=9501:pnld > . Acesso em: 6 ago. 2020 .

BRASIL. Ministério da Educação (MEC). Portaria no 867, de 4 de julho de 2012. Institui o Pacto Nacional pela Alfabetização na Idade Certa e as ações do Pacto e define suas diretrizes gerais. Diário Oficial da União, Brasília, DF, 5 jul. 2012. Seção 1, p. 22.

COLL, C.; MARCHESI, A.; PALACIOS, J. Desenvolvimento psicológico e educação: psicologia da educação escolar. Porto Alegre: Artmed, 2004.

DEPRESBITERIS, L.; TAVARES, M. R. Diversificar é preciso...: instrumentos e técnicas de avaliação da aprendizagem. São Paulo: Senac, 2009.

HOFFMANN, J. Avaliação mediadora: uma prática em construção da pré-escola à universidade. Porto Alegre: Mediação, 2008.

HOFFMANN, J. Avaliar para promover: as setas do caminho. Porto Alegre: Mediação, 2011.

LUDKE, M.; ANDRÉ, M. E. D. A. Pesquisa em educação: abordagens qualitativas. São Paulo: EPU, 1986. (Temas Básicos de Educação e Ensino).

MORTATTI, M. R. L. Um balanço crítico da "Década da Alfabetização" no Brasil. Cadernos Cedes, Campinas, v. 33, n. 89, p. 15-34, jan./abr. 2013.

SILVA. C. S. R. Formas de uso dos novos livros de alfabetização: por que os professores preferem os métodos tradicionais? In: VAL, M. G.; MARCUSCHI, B. (Org.). Livros didáticos de língua portuguesa: letramento e cidadania. Belo Horizonte: Autêntica, 2005.

ZABALA, A. A prática educativa: como ensinar. Porto Alegre: Artmed, 1998.

Magna do Carmo Silva, doutora em Educação pela Universidade Federal de Pernambuco (UFPE), é professora de graduação e da pós-graduação em Educação, e pró-reitora de graduação (Prograd) nessa universidade. Coordena o Grupo de Pesquisas em Alfabetização, Leitura e Escrita: Avaliação, Práticas e Políticas (ALEP), cadastrado no CNPq. Pesquisa na área de Educação, Alfabetização, Formação de Professores, Avaliação. Atuou como formadora e coordenadora da formação de professores na educação básica.

magna_csc@yahoo.com.br

Recebido em 29 de março de 2020

Aprovado em 20 de junho de 2020 